\title{
Spatial repartition of tabanids (Diptera:Tabanidae) in different ecological zones of North Cameroon
}

\begin{abstract}
The different species of tabanids and their zoogeographical distribution in the North Region of Cameroon needs to be updated following the preliminary study of Ovazza and collaborators in 1970. To achieve this, an inventory of tabanids in three key ecological zones of North Cameroon was implemented with a modified Manitoba trap (Sevi), Nzi, Vavoua and Laveissière traps $(n=39)$; identification was made using standard keys. The total number of tabanids captured was 723 , belonging to the following species: Tabanus gratus (42.32\%), Chrysops distinctipennis (19.50\%), T. taeniola $(13.83 \%)$, T. biguttatus $(8.99 \%)$, T. sufis $(8.29 \%)$ and T.par $(7.05 \%)$. The six species identified were common in all the three ecozones. The species in the different genera identified showed significant $(\mathrm{P}>0.05)$ differences in body and wing length. Tabanids abundance was biotope-dependent that is- Zone 26; 282/723 (39.0\%), Zone $27 ; 230 / 723(31.8 \%)$ and Mbele 211/723 (29.2\%). Based on the diversity index of the various tabanid species, Mbele was most diversified in terms of species-type, followed by Zone 27 and lastly by Zone 26. C. distinctipennis and T. sufis were identified in the Northern region, for the first time. This has added to the already existing list of tabanids of Cameroon and will be a necessary element for future control in the North Region of this country.
\end{abstract}

Keywords: Diversity, ecozones, north cameroon, repartition, tabanids
Volume I Issue 2 - 2017

Lendzele SS, 'Abdoulmoumini $\mathrm{M}^{2}{ }^{2}$ Lydie $\mathrm{AYG}^{3}$

'Department of Animal Biology, University of Dschang, Cameroon

${ }^{2}$ Department of Parasitology and Parasitological Diseases, University of Ngaoundéré, Cameroon

${ }^{3}$ Université Félix Houphouët-Boigny, Côte d'Ivoire

Correspondence: Sevidzem Silas Lendzele, Vector-Borne Infectious Disease Unit, Laboratory of Applied Biology and Ecology (VBID-LABEA), Department of Animal Biology, Faculty of Science, University of Dschang, PO Box 067, Dschang,

Cameroon, Email lendzele.jimmy@yahoo.com

Received: July 24, 2017 | Published: August 07, 2017

\section{Introduction}

Tabanids, members of the class Insecta, family Tabanidae, are pests for human and livestock because of their painful and irritating bites, persistent biting behavior and blood contamination. Tabanids can also transmit human and animal disease agents, biologically or mechanically. ${ }^{1-2}$ Horse flies consist of more than 4000 species that are found on all ecological sites with considerable harmful effects. ${ }^{1}$ They are present seasonally in all kinds of landscapes, latitudes/altitude and high populations of these flies have a significant economic impact on outdoor activities, tourism and livestock production. Mechanical transmission is defined as the transfer of pathogens from an infected or contaminated host to a susceptible host; transfer for which there is no biological association between the pathogen and vector. The mechanical transmission can be ensured by arthropods, birds, rats, vampire bats or other animals. Additionally, iatrogenic transmission can be ensured by humans during prophylaxis campaigns for example. These various transmission methods allow the extension of diseases once thought to be transmitted cyclically only. The negligence of such mechanical means in the transmission of pathogens, both in epidemiological studies and eradication campaigns, has led to their incompleteness and failure respectively. Animal trypanosomosis is a good example of diseases transmitted both cyclically by tsetse flies and mechanically by other blood-sucking insects. These elements are the source of an increasing interest in mechanical vectors studies and justify this current study. Several studies have been done on tsetse flies, but little work has been devoted to mechanical vectors (tabanids). The study of horse flies is very difficult, given the vast number of species present in all types of environments and also the volume and complexity of identification keys. The colossal work of Oldroyd in the $1950 \mathrm{~s},{ }^{3-5}$ which followed an identification key in three volumes represented more than a thousand pages of incomparable knowledge about tabanids of the Afro-tropical zoogeographical region; among the many species described, it was difficult to determine a species which could have a significant role in livestock.

These insects have two adverse effects on livestock. Firstly a direct effect by skin lesions (several hundreds of bites per day per animal, pain, secondary infections), blood loss (up to $700 \mathrm{mg}$ /insect in horseflies), visual harassment and noise, and toxic and irritating nature of their saliva. Secondly, indirect effect through the transmission of pathogens (Rickettsia, bacteria, viruses, protozoa and helminths) ${ }^{1}$ in the blood or lymph of their hosts. In contrast to the cyclic transmission (which occurs when the disease agent replicates or develops within the fly prior to transmission), the mechanical transmission is characterized by the fact that there is no evolution, no multiplication of the pathogen in the vector. ${ }^{6}$ The work of Ovazza et al. ${ }^{7}$ on the zoogeographical distribution of tabanids of Cameroon was preliminary and because of climate change and other factors, we thought it wise to reassess the tabanid status in some cattle major rearing areas of Cameroon. The objective of this work was to show the spatial distribution of tabanids in different ecological zones of north Cameroon as an important step for future control.

\section{Materials and methods}

\section{Brief description of the study area}

Geographically, the study area falls within Latitude N 07. 76400 and Longitude E 014.99208 (Figure 1). This area is a pasture area favored by river Vina and Rao with drinking water available all season for sedentary and semi-sedentary cattle herds. Agricultural activities are also important in this poor rural community as well as fishing activities. Hunting grounds merge with pasture areas and wild animals roam around this area. Another striking situation in this site is conflict between the Bororo and German who chase cattle of the latter, entering to graze in their Reserves. It is important to note 
that no eradication intervention efforts were ever implemented in this area despite its degree of infestation in the past that was since 1925 (as reported by MSEG agent of this area in March, 2016 during our survey) and that was the more reason why the area was considered as a tsetse infested area. Based on weather, March is warmest with an average temperature of $36.1^{\circ} \mathrm{C}$ at noon. January is coldest with an average temperature of $15.9^{\circ} \mathrm{C}$ at night. Sora Mboum has no distinct temperature seasons, the temperature is relatively constant during the year. Temperatures usually drop sharply at night. In winter there may be some days it freezes; overall winters are mild in temperature, with the coldest month most often being January. December is on average the month with most sunshine. The wet season has a rainfall peak around August; the dry season is around the month of December. Sora Mboum has a humid ( $>0.65 \mathrm{p} / \mathrm{pet}$ ) climate. The land area is cultivated with crops like maize; most of the natural vegetation is still intact. The landscape is mostly covered with closed to open shrub land, elevated at an altitude of 545 meters. The climate is classified as a tropical savanna (winter dry season), with a tropical dry forest biozone. The soil in the area is high in lixisols (lx), soil with clay-enriched lower horizon, low cec, and high saturation of bases.

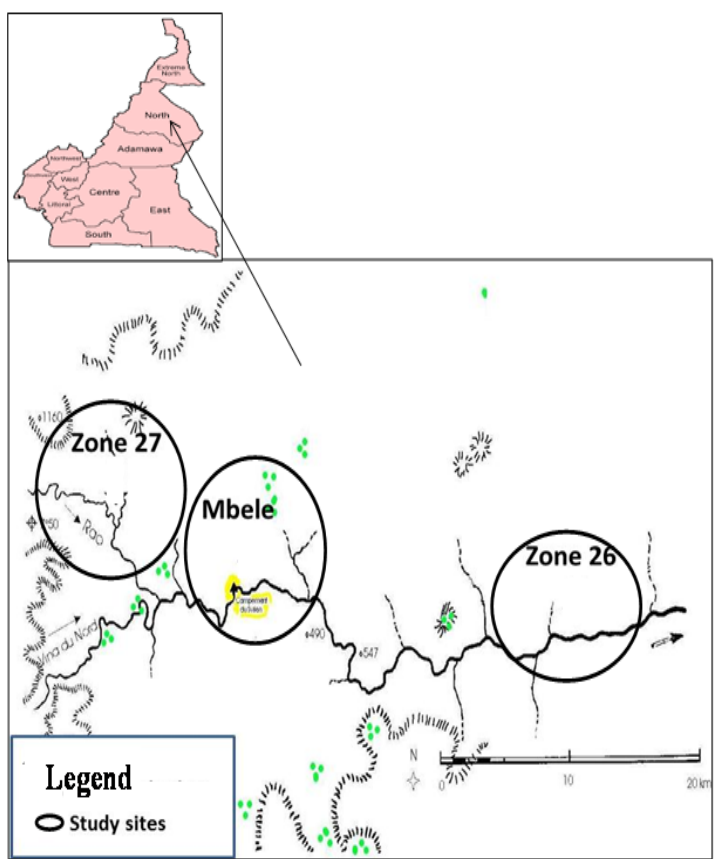

Figure I Map of study area indicating sampling sites.

\section{Tabanid sampling and identification}

A line transect survey was carried out along the river and Rao pasture area using four traps: Sevi (modified Manitoba trap), Nzi, Vavoua and Biconical $(\mathrm{N}=39)$ (Figure 2).

Zones where sampling took place were Zone 26 (Rao), Zone 27 (Syrien Campsite) and Mbele. Traps were displayed in the respective sites as shown (Table 1). All sites were closest to the private German game reserves.

Traps were maintained at $100-500 \mathrm{~m}^{8}$ apart and collection was carried out every evening. Identification was carried out, based on morphological characteristics using published simplified keys summarized by Desquesnes ${ }^{9}$ and Baldacchino et al. ${ }^{10}$ These keys enabled the identification of the most common African tabanid flies up to species level. The trap types and number was not the same and this was because we wanted to maximize the chances of the different fly-types, using different trap-types that were available.

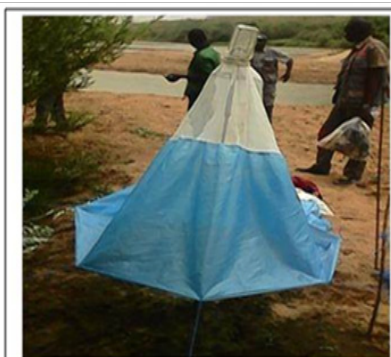

Sevi trap

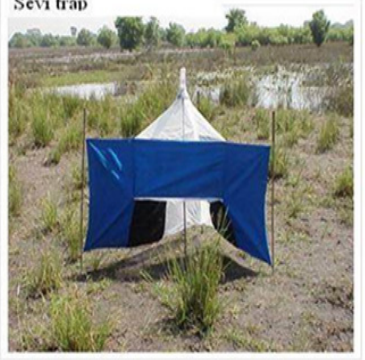

Nzi trap

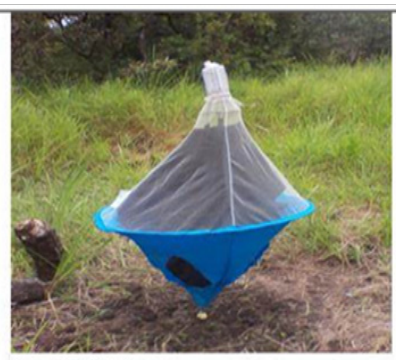

Laveissière trap

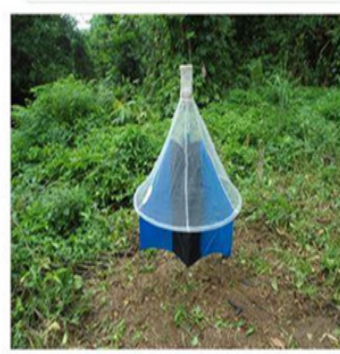

Vavoua trap
Figure 2 Trap-types used for the entomological prospection

Table I Experimental display of traps in the various sampling zones

\begin{tabular}{llllll}
\hline Zones & \multicolumn{2}{l}{ Trap-types } & \multicolumn{2}{c}{ Total } \\
\cline { 2 - 5 } & Sevi & Nzi & Vavoua & Biconical & \\
\hline Zone 26 & 2 & I & 8 & 5 & 16 \\
Zone 27 & 2 & I & 7 & 4 & 14 \\
Mbele & 2 & I & 4 & 2 & 9 \\
Total & 6 & 3 & 19 & I I & 39 \\
\hline
\end{tabular}

\section{Data analysis}

Data collected in the field was analyzed using Excel spread sheet program of Version Windows 2007 and SPSS Version 21.0. ANOVA 1 was used to test for significance of mean body and wing length of tabanid flies captured. All tests were kept at $\mathrm{P}<0.05$ significant level. The diversity index of tabanid species captured in each zone was computed using the diversity index of Margalef (I) as shown:

$$
I=\frac{S-1}{\log N}
$$

Where "S" was the number of species and "N", the total number of individual's harvested ${ }^{11}$ and "I" the diversity index.

\section{Results and discussion}

The different Tabanidae species identified in the North Region of Cameroon

Sub family Chrysopsinae

\section{Genus: Chrysops Meigen, 1803}

\section{a. C. distinctipennis Austen, 1906}

This species was most abundant in the Zone 27 type locality even 
though it was captured in all the zones.

Sub family Tabaninae

\section{Genus: Tabanus Linnaeus, 1758}

\section{b. T. taeniola Palisot de Beauvois, 1807}

It was most abundant in Zone 27, but was common in all the other zones.

\section{c. T. par Walker, 1854}

It was most abundant in Zone 27, but was common in all the other zones.

\section{d. T. sufis Jaennicke, 1567}

It was most abundant in Zone 27, but was common in all the zones considered for the survey.

\section{e. T. gratus Loew, 1858}

It was most abundant in Zone 26 than any other zone even though it was common in all the zones.

\section{f. T. biguttatus Wiedemann, 1830}

It was most abundant in Zone 27 than the others, even though it was common in all the other zones.

The number of tabanids captured in the three study zones was 723 . Based on the frequency of tabanids with study zone, Zone 26 had the highest 282/723 (39.0\%), followed by Zone 27; 230/723 (31.8\%) and Mbele 211/723 (29.2\%) (Table2). The six species of Tabanidae identified, 4 of them belong to the genus Tabanus and one belong to the genus Chrysops. Based on tabanids species specific frequencies, the following fluctuations were observed: T. gratus $(42.32 \%)$, C. distinctipennis (19.50\%), T. taeniola (13.83\%), T. biguttatus (8.99\%), T. sufis $(8.29 \%)$ and $T$. par $(7.05 \%)$ (Table 2).

Table 2 Total number of tabanids captured by species

\begin{tabular}{|c|c|c|c|c|c|}
\hline Species & Mbele & $\begin{array}{l}\text { Zone } \\
26\end{array}$ & $\begin{array}{l}\text { Zone } \\
27\end{array}$ & $\mathbf{N}$ & $\%$ \\
\hline $\begin{array}{l}\text { Tabanus gratus Loew, } \\
1858\end{array}$ & 86 & 130 & 90 & 306 & 42.32 \\
\hline T. par Walker, 1854 & 12 & 21 & 18 & 51 & 7.05 \\
\hline $\begin{array}{l}\text { T. taeniola Palisot de } \\
\text { Beauvois, } 1807\end{array}$ & 34 & 35 & 31 & 100 & 13.83 \\
\hline $\begin{array}{l}\text { T. biguttatus Wiedemann, } \\
\text { I830 }\end{array}$ & 16 & 29 & 20 & 65 & 8.99 \\
\hline T. sufis Jeanicke, I567 & 16 & 24 & 20 & 60 & 8.29 \\
\hline $\begin{array}{l}\text { Chrysops distinctipennis } \\
\text { Austen, } 1906\end{array}$ & 47 & 43 & 51 & $|4|$ & 19.5 \\
\hline Total & 211 & 282 & 230 & 723 & 100 \\
\hline
\end{tabular}

The mean body and wing length of the different species of Tabanidae captured did not show intra and inter-generic significant $(\mathrm{P}>0.05)$ differences (Table 3).

For tabanid species distribution with respect to the three type-localities, $T$. gratus was dominant in all study zones, but $T$. par was the least distributed in all the three zones (Figure 3).
The tabanid species diversity index graph showed that species were highly diversified in Mbele, followed by Zone 27 and lastly by Zone 26 (Figure 4).

Table 3 The mean body and wing length of tabanids captured in North Cameroon.

\begin{tabular}{lll}
\hline Tabanidae & $\begin{array}{l}\text { Mean } \pm \text { SD body } \\
\text { length/mm }\end{array}$ & $\begin{array}{l}\text { Mean } \pm \text { SD wing } \\
\text { length/mm }\end{array}$ \\
\hline Tabanus spp. & & $7.8 \pm 0.45$ \\
T. par & $12.2 \pm 0.45$ & $12 \pm 0.7 \mid$ \\
T. taeniola & $17 \pm 0.7 \mid$ & $10.2 \pm 1.30$ \\
T. biggutatus & $12 \pm 0.44$ & $8.8 \pm 0.45$ \\
T. sufis & $12 \pm 1.58$ & $8 \pm 0.7 \mid$ \\
T. gratus & $10.4 \pm 1.34$ & \\
Chrysops spp. & & $7 \pm 0.7 \mid$ \\
C. & & \\
distinctipennis & $|1 \pm 0.7|$ &
\end{tabular}
SD, Standard Deviation

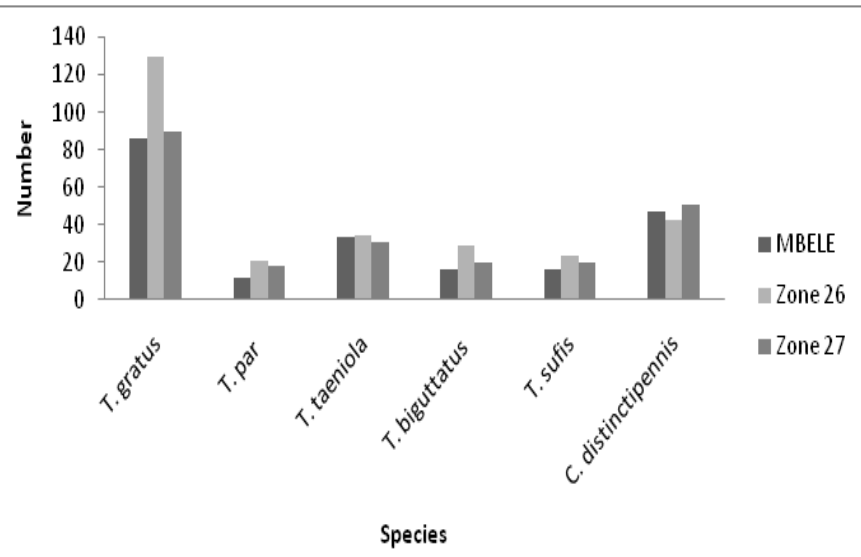

Figure 3 Tabanids species distribution based on zone of capture

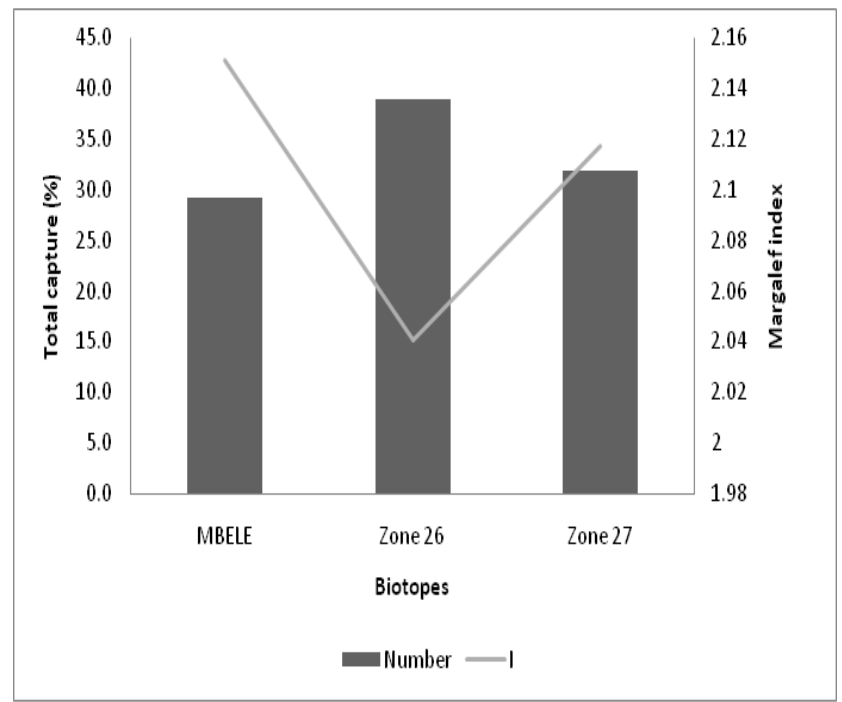

Figure 4 The number of Tabanids captured and their diversity index, I, Margalef index 
The total number of tabanids captured was 723 and this number was lower than 11091 overall tabanids catch reported by Mamoudou et al. ${ }^{12}$ in the different biotopes and sites in the Extreme North of Cameroon. Sevidzem et al. ${ }^{13}$ also reported a scanty catch of tabanids of Faro Game Reserve of Adamaoua with catches lower than that of the present survey. This can be justified by the fact that the number of traps and types used in the present study was greater than that used in the previous studies. Based on the distribution of tabanids captured with biotope, it was realised that Zone 26 recorded the highest abundance as compared to the other two zones. The possible reason for this difference was that traps of Zone 26 were greater than those in the other zones. The species captured in this present exercise included five species of the genus Tabanus which were: T. taeniola, T. par, T. sufis, T. gratus and T. biguttatus and only one species of the genus Chrysops was identified and was $C$. distinctipennis. This indicates that the present study has updated the list of tabanids which were not identified by Mamoudou et al. ${ }^{12}$ like $C$. distinctipennis, $T$. biguttatus and $T$. sufis but one genus included in their catches did not figureout in the catches of our present survey. This might be explained by the fact that different survey periods in different bio-geographical locations might contribute to the occurrence of different species/ genera of tabanids in different geographical areas due to as similar environmental conditions acting during those periods. This present study also updates the list of tabanids of Cameroon since Ovazza et al. ${ }^{7}$ did not report $C$. distinctipennis in his findings in Cameroon. The absence of this particular Chrysops species confirms the findings of Oldroyd $\mathrm{d}^{14}$ who reported that «All the information at my disposa1 indicates that $C$. distinctipennis is not found in the forest but is a species of the Savannah just outside the forest belt» ${ }^{14}$ and because of the possible confusion between C. stigmaticalis and C. distinctipennis, Oldroyd $^{5}$ reported that $C$. distinctipennis may occur in fringe areas in the southern part of Cameroon (Oldroyd). This author reported that C. distinctipennis was a savannah species and their capture in the savannah of North Cameroon was expectant.

T. gratus exhibited a higher prevalence in all the three biotopes than any other species and the lower one was T. par. This means that the month of March as well as climatic conditions that accompanied it did not favor high distribution of this particular species (T. par) in the ecological zones of North Cameroon. The fact that $T$. par was the least in the collection is in line with the studies carried out in the Extreme North of Cameroon during this same month which reported T. par to be the least Tabanus sp. in their collection. ${ }^{12}$ From the species diversity index of each zone, Mbele showed a high diversity of tabanid types than the other zones. This marked difference was due to the fact that, high cattle density and other hosts (such as dogs, domestic fowls, birds and wild bovidae) attracted more tabanids to this area with several alternative hosts than the other zones. $C$. distinctipennis was the second most frequent after $T$. gratus and their presence in high numbers depicted that the area might be a foci for Loasis infections. This suggestion was confirmed by an MSEG agent who had previously worked on a project with the Germans on the vectors of loasis and said that the area harbored this disease. Their possibility to be biologically transmitted by $C$. distinctipennis has already been reported..$^{15}$ The Vina du Nord pasture area was reported in the work of Gerard et al. [16] as being a focal area for onchocerchiasis control and this disease is commonly wired by members of the Chrysops spp. ${ }^{15}$ including the recently identified species in this work. The recent identification of $C$. distinctipennis and Simulium spp. in the area suspected the existence of the disease in the area since they are vectors of loa loa filariasis.

\section{Conclusion}

The six species of Tabanidae identified, four of them belong to the genus Tabanus and one belong to the genus Chrysops. T. gratus was the most abundant species within the genus Tabanus and in the whole collection; hence main mechanical vector of cattle pathogens especially cattle trypanosomosis. C. distinctipennis as the second most abundant fly caught, indicating the risk of loa loa transmission in these three ecological zones. Zone 26 harbored high tabanid niches which portrayed its high pathogen transmission risk. Mbele showed a high diversity of the various members of the Tabanidae family captured and which also portrayed its danger. Control interventions in this area should include the pitching of targets in the protected zones, followed by the creation of a buffer zone consisting of a barrier line made up of Deltametrin coated screens and the regular application of ectoparasiticides (Pour-on formulations) by farmers themselves in order to stop vector-host contact as well as subsequent pathogens transmission. ${ }^{16}$

\section{Acknowledgments}

We are grateful to the Special Mission for the eradication of glossines (MSEG) for their material and technical assistance. We are also thanking the authorities at the MSEG laboratory for their assistance in the identification of flies collected on the field. We are also grateful to Dr Desquesnes for proof reading the manuscript and confirming samples collected on the field.

\section{Conflict of interest}

Authors declare there is no conflict of interest.

\section{References}

1. Foil LD. Tabanids and vectors of disease agents. Parasitology Today. 1989;5(3):88-96.

2. Krinsky WL. Animal disease agents transmitted by horse flies and deerflies (Diptera: Tabanidae). J Med Entomol. 1976;13(3):225-275.

3. Oldroyd H. The Horse-flies of the Ethiopian Region (Diptera: Tabanidae). 1. Haematopota and Hippocentrum. British Museum (Natural History), London, UK; 1952. p. 226.

4. Oldroyd H. The horse-flies (Diptera: Tabanidae) of the Ethiopian region. II. Tabanusand related genera. British Museum (Natural History), London, UK; 1954. p. 341.

5. Oldroyd H. The horse-flies (Diptera: Tabanidae) of the Ethiopian region. III. Subfamilies Chrysopinae, Scepsidinae and Pangoniinae and a revised classification. British Museum (Natural History), London, UK; 1957. p. 489.

6. Mullens. Horse flies and deer flies (Tabanidae). In: Mullen G, Durden L, editors. Medical and Veterinary Entomology. Academic Press, San Diego, USA; 2002. p. 263-277.

7. Ovazza M, Mouchet J, Rickenbach A. Tabanidae du Cameroun II. Les espèces connues et leur répartition. Cahier OHSTOM séries Entomologie Médicale. 1970;8(4):93-105.

8. Mihok S. The development of a multipurpose trap (the Nzi) for tsetse and other biting flies. Bull Entomol Res. 2002;92(5):85-403.

9. Desquesnes M, Dia M, Acapovi G, et al. Les vecteurs mécaniques de trypanosome animales, généralités, morphologie, biologie, impactes et contròle: Identification des espèces les plus abondantes en Afrique de l'ouest, In: CIRDES\& CIRDES Ed. Bobo Dioulasso, Burkina-Faso, 2005. p. 68 
10. Baldacchino F, Marc D, Steve M, et al. Tabanids: Neglected subjects of research, but important vectors of disease agents. Infection, Genetics and Evolution 2014;28:596-615.

11. Légendre L, Légendre P. Ecologie numérique. Le traitement multiple des données écologiques, Paris, France; 1979. p. 197.

12. Mamoudou A, Mbanwei M, Fongho SP, et al. Tabanids (Diptera: Tabanidae) fauna composition in different sites and biotopes of FarNorth, Cameroon. Journal of Biology and Nature. 2016;6(3):146-154.

13. Sevidzem SL, Mamoudou A, Woudamyata AF, et al. Contribution to the knowledge of ecodiversity and density of tsetse (Glossinidae) and other biting flies (Tabanidae and Stomoxyinae) in the fly controlled-infested livestock/wild life interface of the Adamawa plateau-Cameroon. Journal of Entomology and Zoology Studies. 2015;3(5):329-333.
14. Oldroyd H. Symposium on Loasis. II. Some comments on the species of Chrysops bred and collected at Kumba, British Cameroons. Transactions of the Royal Society of Tropical Medicine and Hygiene. 1955;49:111-114.

15. Duke BOL. The development of Loa in flies of the genus Chrysops and the probable significance of the different species in the transmission of loiasis. Transactions of the Royal Society of Tropical Medicine and Hygiene. 1955;49(2):115-121.

16. Gerard JJM, Borsboom BA, Boatin N, et al. Impact of ivermectin on onchocerchiasis transmission: assessing the empirical evidence that repeated ivermectin mass treatments may lead to elimination/eradication in West-Africa. Filarial Journal. 2003;2:8. 